\title{
The effect of brushing with Salvadora persica (miswak) sticks on salivary Streptococcus mutans and plaque levels in children: a clinical trial
}

\author{
Heba J. Sabbagh ${ }^{1 *}$ (D), Khalil S. AlGhamdi ${ }^{2}$, Hattan T. Mujalled ${ }^{3}$ and Sara M. Bagher ${ }^{1}$
}

\begin{abstract}
Background: The aim of the randomized double-blinded clinical trial was to evaluate the effect of tooth brushing with Salvadora persica (miswak) sticks on Streptococcus mutans count and the mean plaque score relative to brushing with fluoridated tooth paste (FTP).

Methods: Our sample included 94 healthy, high caries-risk, 8 to 9-year-old students recruited from a government school, in Jeddah, Saudi Arabia between February and April 2016. Subjects were randomly grouped into test (provided with miswak sticks) and control groups (provided with FTP and soft brushes). Both groups were introduced to a preparatory period (PPP) of 3 weeks. Plaque score and saliva sampling were conducted prior to the PPP and in follow-up visits by a single, calibrated and blinded dentist.
\end{abstract}

Results: Both groups showed a statistically significant decrease in the mean plaque score across the study $(P=0.007$ and $P=0.001$, respectively). In addition, subjects in the test group with abundant S. sanguinis increased from zero to six after 3 months.

Conclusions: Salvadora Persica (miswak) and brushing with FTP significantly reduced plaque scores among school children. In addition, Salvadora persica was found to change the proportions of salivary bacteria in favor of species with less risk of inducing caries.

Trial registration: ClinicalTrials.gov ID \#: NCT04137393.

Keywords: Miswak, Plaque score, Salvadora Persica, Salivary mutans Streptococci, And school children

\section{Background}

Dental caries is a microbial disease that originates from bacterial metabolic acid release and diffuses into enamel and dentine, dissolving the mineral [1]. Although the etiology of caries is multifactorial, mutans Streptococci (Streptococcus mutans, Streptococcus sobrinus) are reportedly the principal bacteria related to the disease [2]. Preventing and controlling dental caries can be accomplished by either oral hygiene measures affecting dental plaque (the main reservoir for oral bacteria) or a direct replacement of cariogenic with non-cariogenic colonies.

\footnotetext{
* Correspondence: hsabbagh@kau.edu.sa

${ }^{1}$ Pediatric Dentistry Department, King Abdulaziz University, Jeddah, Saudi Arabia

Full list of author information is available at the end of the article
}

However, such preventive measures may be limited to children of high socioeconomic status [3], while the dental disease burden of illness disproportionately affects children of lower socioeconomic status [4].

For thousands of years, plants have been used for dental hygiene and therapeutic practices [5]. The use of chewing sticks from Salvadora persica (miswak) plants is widespread in low socioeconomic areas in Asia, Africa, South America, and the Middle East, including Saudi Arabia [6]. Moreover, miswak is known as the "toothbrush tree"; studies reported that it contains fluoride, chloride, silica, and vitamin $\mathrm{C}$, in addition to other healthy components [7].

Ezoddini-Ardakani et al., 2006 reported that Salvadora persica had a significant effect on preventing dental 
caries in second-year high school students in Iran [8]. Other studies reported a consistent association between the use of miswak and a decrease in oral bacteria [9-13]. However, a comprehensive assessment of the association between the plant and its prevention of dental caries among young children has yet to be conducted.

The present clinical trial therefore aimed to evaluate the effect of tooth brushing with Salvadora persica sticks on Streptococcus mutans count and the mean plaque score relative to brushing with fluoridated toothpaste (FTP) in a group of 8 to 9-year-old children at high caries risk.

\section{Methods}

This randomized parallel double-blinded clinical trial was conducted at a local primary school in Jeddah, Saudi Arabia after the research proposal was approved by the research ethics committee of King Abdulaziz University Faculty of Dentistry (KAU), Jeddah, Saudi Arabia (06616). It was registered on ClinicalTrials.gov with the ID number of "NCT04137393".

\section{Subject selection}

Our sample included 8 to 10 -year-old male students recruited from Alshati Elementary Government School, in Jeddah, Saudi Arabia, between February and April 2016. The sample size was calculated using OpenEpi online sample size calculation (http://www.openepi.com/SampleSize/SSCohort.htm). The risk/prevalence difference was calculated according to Ezoddini-Ardakani et al,, 2010, who reported that the difference in decayed, missing, and filled permanent teeth due to caries (DMFT) between individuals using miswak and those using a tooth brush was 55\% [8]. This risk/prevalence difference gave us an effective sample size of 60 (30 test and 30 controls). However, to avoid sample regression in the follow-up visits, the sample size was increased to 94 .

The criteria for inclusion were children at high-risk of developing caries with at least one cavity detected clinically by a trained dentist prior to participation in the study. All subjects with systemic disorders such as diabetes, hypertension, or sleeping disorders; subjects with regular use of medication; and children who received antibiotics during the month prior to the clinical examination were excluded from the study.

\section{Method}

Prior to participating in the study, all children underwent a clinical examination (screening) administered by a trained dentist. Children diagnosed with at least one caries were considered to be at high risk based on the Caries Risk Assessment (CAT) [14] and thereby qualified for the study.
An educational lecture on oral hygiene and diet was provided to the children and class teachers by a single trained dentist. Arabic consent forms accompanied by a letter explaining the aim of the study were distributed to the parents of the qualified children. Parents who agreed to allow their children to participate were randomly allocated to either the test or control group classes using a coin toss. Participant enrollment and group assignments were carried out by the investigators with the help of external personnel assigned by the school administration. The distribution of children to cases and controls was concealed until the time of intervention with the external personnel.

The dentists visited the school after 1 week and distributed miswak sticks, uniform in length and width, supplied fresh from Makkah Miswak Central Market, Saudi Arabia, to the subjects in the test group. These miswaks were the roots of "Arak Siwak" plants that were originally plant in the south of Saudi Arabia. Subjects in the control group were supplied with FTP with a fluoride concentration of $1450 \mathrm{ppm}$ and small, soft Oral B manual flat trim brushes.

In the test group, subjects were instructed to brush with the miswak using the rolling technique, advised to use it three times a day under a parent's supervision, and shown how to keep it fresh by cutting off the edge of the miswak every day and storing it in the refrigerator at night. Subjects in the control group were also instructed in the rolling technique of brushing and advised to brush three times a day under a parent's supervision.

To ensure that all included subjects received the same standard of care, both groups were introduced to a preparatory period (PPP) of 3 weeks. Saliva samples and plaque levels were obtained from the qualified subjects prior to the PPP (baseline). During the PPP, both groups performed daily supervised brushing. Morning sessions were monitored by two trained dentists from KAU in the first week and by the trained class teachers during the following 2 weeks; brushing was supervised by the class teachers. At the end of the PPP, plaque scores were obtained for the second time. Plaque scores were then assessed for the third time at the 3 months follow-up. Saliva samples were also obtained from the subjects at 1 month and 3 months follow-up.

The same trained dentists visited the school at least twice a week following the PPP for oral hygiene supervision. Extra tooth brushes and miswak sticks were provided in case any subject forget to bring his. Subjects were provided with a compliance chart and stickers. Each time the subject brushed at school, a sticker was placed by the supervising teacher. At home, the stickers were placed by the supervising parent. Only subjects who were available through the research period for 
school brushing were included in the study. Children who were absent for more than 5 days were excluded from the study. In addition, subjects who took antibiotics during the period of study were excluded from the study.

\section{Clinical examination}

Examination for dental caries and plaque levels was conducted for the subjects during screening in optimal light using a mouth mirror and explorer by a single trained dentist. Diagnosis of dental caries was conducted based on the WHO criteria of 1987 and expressed as dmft for deciduous teeth and DMFT for permanent teeth (WHO 1978) [15]. Plaque levels were assessed using the Simplified Oral Hygiene Index by Green Vermillion (debris index) [16]. The examiner and laboratory were blinded to the subjects' groups.

\section{Saliva samples}

Saliva samples were collected from each participant for the assessment of salivary bacterial levels. Saliva sampling was performed prior to the PPP (baseline), at one and 3 months follow-up. The process was carried out between 7 and $11 \mathrm{am}$ for a period of $15 \mathrm{~min}$ per subject. The subjects were instructed not to brush, eat, drink, or chew gum for $2 \mathrm{~h}$ prior to sampling.

\section{Microbiology assay}

Literature was reviewed for microbes related to oral diseases, which include Streptococcus colonies [15, 17]. Accordingly, each saliva sample was examined using the quantitative colony count per colony forming unit $(\mathrm{CFU} / \mathrm{ml})$ *. The agar surface was wetted with saliva and then placed in a test vial, which was incubated at $37^{\circ} \mathrm{C}$ for $48 \mathrm{~h}$. The count of variance of all Streptococcus colonies was obtained. Findings of $10^{5} \mathrm{CFU}$ or more of Streptococcus mutans indicated a high risk of developing caries, and findings of less than $10^{5} \mathrm{CFU}$, a low risk of developing caries. The frequency of subjects with high Streptococcus colonies was assessed. The laboratory technician was blinded to the subjects' groups.

\section{Calibration}

To reach good intra-examiner reliability, calibration of the examiner was conducted prior to the clinical examination. Ten randomly selected children were examined to assess their caries and plaque levels. Re-examination of the subjects was conducted after 15 days and the level of agreement between the two measurements was assessed using the Kappa method. We found 100\% agreement with a kappa score of $1(p<0.001)$, indicating perfect agreement.

\section{Statistical analysis}

The paired Samples T-test was used to compare between the mean plaque score of test and controls at different time periods (baseline, end of the PPP, and the 3 months follow-up). In addition, Chi-square test at a 0.05 level of significance, odds ratio (OR), and 95\% confidence interval (CI) was used to compare between the frequencies of children with Streptococcus colonies of $10^{5} \mathrm{CFU}$ or higher in the different study groups at different time periods (baseline, one, and 3 months follow-up).

\section{Results}

A total of 120 children were screened for the inclusion and exclusion criteria, resulting in 94 subjects enrolled in the study. Out of them, fourteen were absent for 5 days or more, and seven were excluded from the salivary bacterial analysis because they received antibiotics during the study period. This yielded 80 (37 test and 43 controls) subjects who were assessed for plaque levels and 73 (34 test and 39 controls) subjects who were assessed for salivary bacterial levels. Subject allocation and follow-up according to the Consolidated Standards of Reporting Trials (CONSORT) guidelines are illustrated in Fig. 1.

The dmft/DMFT mean score and standard deviation $( \pm \mathrm{SD})$ for the test group was $7.4( \pm 3.82)$, while that for the control group was 8.14 ( \pm 3.94$)$; no significant differences were found $(P=0.37)$.

The mean plaque score $( \pm S D)( \pm S D)$ for the test group increased significantly after the PPP: from $1.31( \pm$ $0.61)$ to $1.67( \pm 0.62)(P=0.04)$. On the other hand, the mean plaque score $( \pm \mathrm{SD})$ for the control group increased from $1.53( \pm 0.75)$ to $1.75( \pm 0.68)$ over the same period; the difference was not statistically significant $(P=0.29)$. However, both miswak and control group subjects showed a statistically significant decrease in mean plaque scores $( \pm \mathrm{SD})$ across the study $(P=0.007$ and $P=0.00$, respectively). In addition, there were no statistically significant differences in mean plaque scores $( \pm \mathrm{SD})$ between the miswak and control groups prior to the PPP $(P=0.56)$, after the PPP $(P=0.44)$, or at the 3 month follow-up $(P=0.478)$ (Table 1$)$.

Regarding bacterial count, all subjects exhibited a high level of Streptococci colonies both prior to the PPP and after the PPP (more than or equal to $10^{5}$ ) (Table 2). In the test group, S. mutans had the highest frequency: $87.5 \%$ prior to the PPP. However, the frequency of S. mutans decreased to $73 \%$ and S. sanguinis increased to $13.5 \%$ after the PPP. At the 3-month follow-up, the S. mutans frequency increased to $82.4 \%$. On the other hand, in the control group, the frequencies of S. mutans, S. sanguinis, and other bacteria were $76.7,11.6$, and $11.6 \%$, respectively. After the PPP, the frequency of S. mutans increased to $83.7 \%$, while that of S. sanguinis 


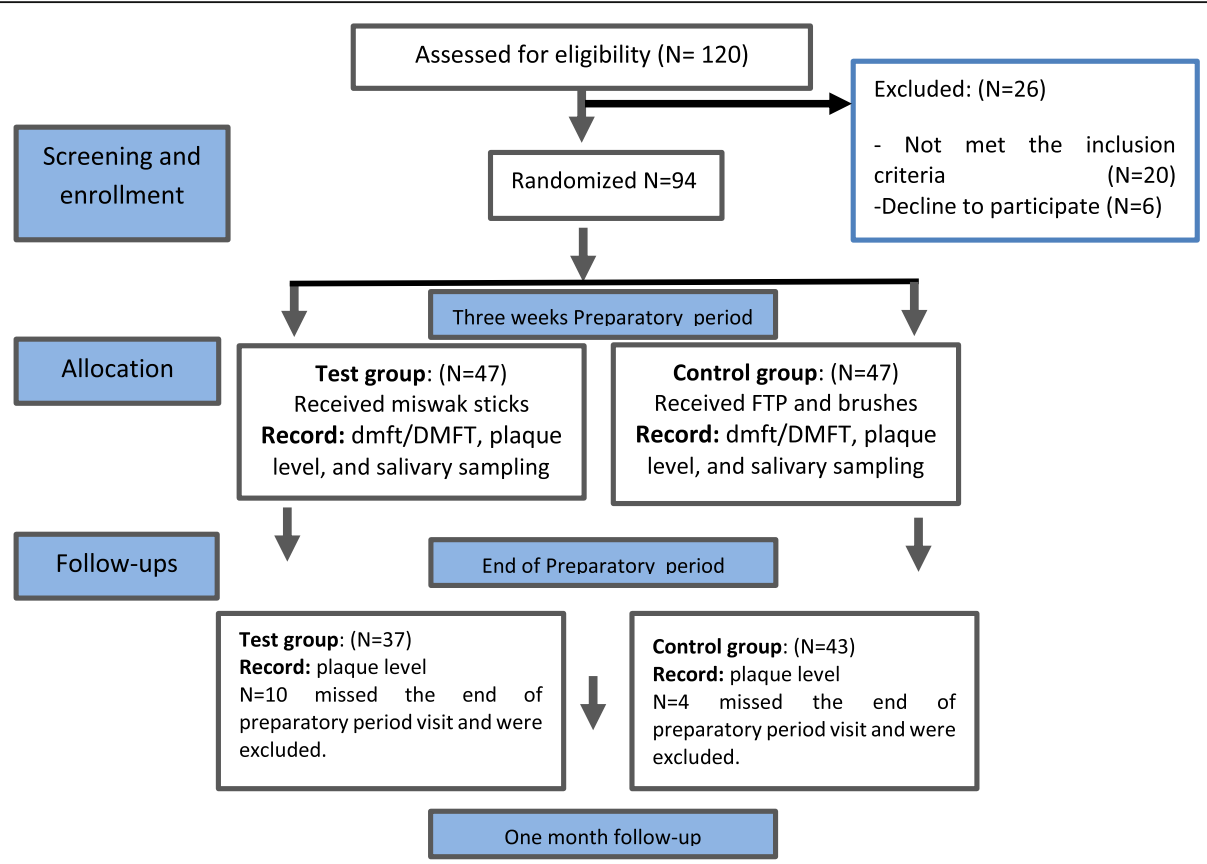

\begin{tabular}{|c|c|}
\hline $\begin{array}{l}\text { Test group: ( } \mathrm{N}=34) \\
\text { Record: saliva sampling } \\
\mathrm{N}=3 \text { either missed the one month } \\
\text { follow-up for saliva collection or } \\
\text { received antibiotics and were } \\
\text { excluded. }\end{array}$ & $\begin{array}{l}\text { Control group: ( } \mathrm{N}=39 \text { ) } \\
\text { Record: saliva sampling } \\
\mathrm{N}=4 \text { either missed the one month } \\
\text { follow-up for saliva collection or } \\
\text { received antibiotics and were } \\
\text { excluded. }\end{array}$ \\
\hline \multicolumn{2}{|c|}{ Three months follow-up } \\
\hline $\begin{array}{l}\text { Test group: } \\
\text { Record: } \begin{array}{l}\text { Plaque level }(N=37) \\
\text { Saliva sample }(N=34)\end{array}\end{array}$ & $\begin{array}{c}\text { Control group: } \\
\text { Record: } \text { Plaque level }(\mathrm{N}=43) \\
\text { Saliva sample }(\mathrm{N}=39)\end{array}$ \\
\hline
\end{tabular}

Fig. 1 Flow chart for the study sample according to Consolidated Standards of Reporting Trials (CONSORT) guidelines

and other bacteria decreased to 7 and $9.3 \%$, respectively. After the 3-month follow-up, both S. mutans and S. sanguinis frequencies increased to 89.7 and $10.3 \%$, respectively (Table 2).

When comparing the test group to the control group in the three periods, we observed more subjects who experienced a decrease in the frequency of high $S$. mutans and an increase in S. sanguinis levels in the test group as compared to the control group (Table 3).

\section{Discussion}

Several studies have assessed miswak and its effect on oral health [9-13]. However, to overcome the complexity of studying oral bacteria [10], most studies were

Table 1 Comparison of mean plaque scores between baseline, after the preparatory period, and at the 3-month follow-up

\begin{tabular}{llll}
\hline Period of sample recruitment & Test group $(\boldsymbol{n}=37)^{\mathbf{b}}$ & Control group $(\boldsymbol{n}=43)^{\mathbf{b}}$ & $1.53( \pm 0.75)$ \\
\hline Prior to the preparatory period (baseline) & $1.3( \pm 0.61)$ & $1.75( \pm 0.68)$ \\
After the preparatory period & $1.67( \pm 0.62)$ & $\mathbf{0 . 2 9}$ \\
$\boldsymbol{P}$ value & \\
3-month follow-up & $\mathbf{0 . 0 4 *}$ & $1.29( \pm 0.47)$ \\
$\boldsymbol{P}$ value*** & $1.11( \pm 0.47)$ & 0.44 \\
\hline
\end{tabular}

bless than the total number, children were absent $(N=14)$

* Significant $P$ value $<0.05$

* Compared to the base line "prior to the preparatory period"

*** Compared to "after the preparatory period" 
Table 2 Comparison between the bacterial count at baseline, after the preparatory period, and at the 3-month follow-up

\begin{tabular}{|c|c|c|c|c|c|}
\hline Period & S. mutans & S. sanguinis & Other & Total & $\boldsymbol{P}$ value \\
\hline \multicolumn{6}{|l|}{ Test group } \\
\hline Prior to the preparatory period (baseline) ${ }^{\mathbf{b}}(\boldsymbol{N}=\mathbf{4 7})$ & $32(86.5)$ & 0 & $5(13.5)$ & $37(100)$ & \\
\hline 1-month follow-up ${ }^{b}(N=34)$ & $27(73)$ & $5(13.5)$ & $5(13.5)$ & $37(100)$ & 0.6 \\
\hline 3-month follow-up ${ }^{\mathbf{b}}(\boldsymbol{N}=\mathbf{3 4})$ & $28(82.4)$ & $6(17.6)$ & 0 & $34(100)$ & 0.88 \\
\hline \multicolumn{6}{|l|}{ Control group } \\
\hline Prior to the preparatory period (baseline) ${ }^{\mathbf{b}}(\boldsymbol{N}=\mathbf{4 7})$ & $33(76.7)$ & $5(11.6)$ & $5(11.6)$ & $43(100)$ & \\
\hline 1-month follow-up ${ }^{b}(N=39)$ & $36(83.7)$ & $3(7)$ & $4(9.3)$ & $43(100)$ & 0.078 \\
\hline 3-month follow-up ${ }^{b}(N=39)$ & 35 (89.7) & $4(10.3)$ & 0 & $39(100)$ & 0.464 \\
\hline
\end{tabular}

b less than the total number, children were absent $(N=14)$ or received antibiotics during the study period $(N=7)$

either conducted in vitro $[11,12]$ or assessed the effect of miswak on gingival health, which requires a relatively short time interval [13]. Thus, the literature features a dearth of high-quality studies on children, who require continuous assessment and supervision of oral-hygiene compliance. In addition, as miswak-use training is not included in the American Academy of Pediatric Dentistry (AAPD) anticipatory guidelines [18], children do not know how to efficiently use it for plaque removal. This study was therefore designed to overcome these limitations by recruiting children at an age when training for oral hygiene according to the AAPD guideline for oral hygiene (AAPD 2016) was possible and only supervision was needed (8 years old) [18]. In addition, a three-week PPP was arranged for oral hygiene training by two trained dentists; further, an ADA-based modified rolling method for brushing was also taught.

Our sample was selected from the Alshati elementary government school, where the children exhibited high $\mathrm{dmft} / \mathrm{DMFT}$, plaque scores, and mutans Streptococci levels, to assess the effect of miswak on children at high risk of developing caries. In addition, the children were all boys, who generally pay less attention to oral health care than girls do [19].
We found a significant preliminary increase in plaque score during the PPP in the test group. However, this increase was reversed significantly, and the children who used the miswak showed a similar ability to remove plaque as did those who used FTP after the 3 months of use. This indicates a lack of knowledge among children regarding the mechanical brushing method required by the miswak and the importance of education and training.

In addition, the number of children with an increase in S. sanguinis and a decrease in S. mutans rose after the use of the miswak, a finding that was not observed in the control group. As both S. mutans and S. sanguinis are related to the status of caries level in subjects, and the latter is associated with healthy tooth surfaces but not with caries $[20,21]$, our results suggest that miswak attenuated cariogenic bacterial colonies.

The findings of the present study therefore suggest that FTP could be replaced by miswak as an antiplaque and antibacterial agent. In addition, the results call for immediate action on the part of dentists to educate their patients on miswak use, especially in communities where miswak is a more convenient brushing method than FTP. This study also recommends the rolling technique

Table 3 Comparison between Streptococcus-colonies count at baseline, one, and 3-month follow-ups

\begin{tabular}{|c|c|c|c|c|}
\hline Period & & Test group n (\%) & Control group n (\%) & $\begin{array}{l}\boldsymbol{P} \text { value } \\
\text { OR }(95 \% \mathrm{Cl})\end{array}$ \\
\hline \multicolumn{5}{|l|}{ Streptococcus colonies } \\
\hline \multirow{3}{*}{$\begin{array}{l}\text { Prior to preparatory period (baseline) Test }(N=47) \\
\text { Control }(N=47)\end{array}$} & S. mutans & $32(86.5)$ & $33(76.7)$ & a \\
\hline & S. sanguinis & 0 & $5(11.6)$ & \\
\hline & Others & $5(13.5)$ & $5(11.6)$ & $P=0.960 .97(0.25-3.67)$ \\
\hline \multirow{3}{*}{$\begin{array}{l}\text { 1-month follow-up } \\
\text { Test }(N=34) \\
\text { Control }(N=39)\end{array}$} & S. mutans & $27(73)$ & $36(83.7)$ & $P=0.30 .45(0.09-2.05)$ \\
\hline & S. sanguinis & $5(13.5)$ & $3(7)$ & \\
\hline & Others & $5(13.5)$ & $4(9.3)$ & $P=0.4760 .6(0.15-2.45)$ \\
\hline \multirow{3}{*}{$\begin{array}{l}\text { 3-month follow-up } \\
\text { Test }(N=34) \\
\text { Control }(N=39)\end{array}$} & S. mutans & $28(82.4)$ & $35(89.7)$ & \\
\hline & S. sanguinis & $6(17.6)$ & $4(10.3)$ & $P=0.360 .53(0.14-2.07)$ \\
\hline & Others & 0 & 0 & a \\
\hline
\end{tabular}

a: not applicable because one of the input cells contains a value of 0

*** the total number (73) less than 80 because of children who were either absent or took antibiotics 
for miswak use. Moreover, it introduces an oral health school program using miswak which helps to facilitate the performance of oral hygiene by children with no additional requirements other than obtaining the miswak stick itself. The most important strength of this clinical trial is its support of recommendations of consistent oral hygiene supervision and the 3-week PPP. Additional future studies with larger sample sizes and longer followup periods are needed, especially on medically compromised patients.

\section{Conclusion}

Salvadora persica and bruising with FTP significantly reduced plaque scores among school children. In addition, Salvadora persica was found to change the proportions of salivary bacteria in favor of species with a lower risk of inducing caries.

\begin{abstract}
Abbreviations
AAPD: American Academy of Pediatric Dentistry; ADA: American Dentistry Association; CAT: Caries-risk Assessment Tool; CFU: Colony Forming Unit; DMFT: Decayed, Missing and Filled Teeth; FTP: Flourided Tooth Paste; KAU: King Abdulaziz University; PPP: Preparatory Period; WHO: World Health Organization
\end{abstract}

\section{Acknowledgements}

Not Applicable.

\section{Consent to publish}

Written informed consent for publication was obtained and approved by the KAUFD ethical committee. A copy of the consent form is available for review by the Editor of this journal if requested from the corresponding author.

\section{Authors' contributions}

HS contributed in designing the study, acquisition, collecting the data, interpretation of the data, writing the material and method of the paper. KA contributed in designing the study, examining the patients, collecting the samples, and contributed in writing the paper. HM contribute in designing the study, examining the patients, collecting the samples, and contributed in writing the paper. SB contributed in writing the paper and final editing. All Authors read and approved the final manuscript.

\section{Funding}

This project was funded by the Deanship of Scientific Research (DSR), King Abdulaziz University, Jeddah, under grant no. (G:394-165-1439). The funding role included providing the materials for the research and supporting the researchers. However, it did not influence the research design, interpretation of the data, or writing of the manuscript.

\section{Availability of data and materials}

The datasets used and/or analyzed during the current study are available from the corresponding author upon reasonable request.

\section{Ethics approval and consent to participate}

Ethical approval was obtained from the ethics committee of KAUFD (066-16) for this study. In addition, written informed consent was obtained from all participants. Parents received an Arabic consent and a letter explaining the aim, design, and methodology of the study.

\section{Competing interests}

The authors declare that they have no competing interests.

\section{Author details}

'Pediatric Dentistry Department, King Abdulaziz University, Jeddah, Saudi Arabia. ${ }^{2}$ Bani Kabir Primary Health care Centre, Baljurshi Health Sector,
Ministry of Health, Albaha, Saudi Arabia. ${ }^{3}$ King Abdulaziz University, Jeddah, Saudi Arabia.

Received: 18 December 2019 Accepted: 9 February 2020

Published online: 13 February 2020

\section{References}

1. Bowen WH, Birkhed D. Dental caries: Dietary and microbiology factors. In: Granath L, McHugh WD, editors. Systematized Prevention of Oral Disease: Theory and practice. Boca Raton: CRC Press; 1986. p. 19-41.

2. Ge Y, Caufield PW, Fisch GS, Li Y. Streptococcus mutans and Streptococcus sanguinis Colonization Correlated with Caries Experience in Children. Caries Res. 2008;42:444-8.

3. Ozdemir D. Dental caries: the most common disease worldwide and preventive strategies. Int J Microbiol Res Rev. 2017;7:340-4.

4. Rowan-Legg A. Canadian Paediatric society, community Paediatrics committee. Oral health care for children - a call for action. Paediatr Child Health. 2013;18:37-50.

5. More G, Tshikalange TE, Lall N, Botha F, Meyer JJM. Antimicrobial activity of medicinal plants against oral microorganisms. J Ethnopharmacol. 2008;119:473-7.

6. Husain A, Khan S. Miswak: The miracle twig. Arch Med Heal Sci. 2015;3:152.

7. Abhary M, Al-Hazmi AA. ScienceDirect antibacterial activity of Miswak (Salvadora persica L.) extracts on oral hygiene-NC-ND license. J Taibah Univ Sci. 2016;10:513-20.

8. Ezoddini-Ardakani F. Efficacy of Miswak (salvadora persica) in preventing dental caries. Health. 2010:2:499-503.

9. Malik A, Shaukat M, Qureshi A, Abdur R. Comparative effectiveness of chewing stick and toothbrush: a randomized clinical trial. N Am J Med Sci. 2014;6:333.

10. Li J, Quinque D, Horz H-P, Li M, Rzhetskaya M, Raff JA, Hayes MG, Stoneking M. Comparative analysis of the human saliva microbiome from different climate zones: Alaska, Germany, and Africa. BMC Microbiol. 2014;14:316.

11. Al-Sohaibani S, Murugan K. Anti-biofilm activity of Salvadora persica on cariogenic isolates of Streptococcus mutans : in vitro and molecular docking studies. Biofouling. 2012;28:29-38.

12. Moeintaghavi A, Arab H, Khajekaramodini M, Hosseini R, Danesteh $H$, Niknami $\mathrm{H}$. In vitro antimicrobial comparison of chlorhexidine, persica mouthwash and miswak extract. J Contemp Dent Pract. 2012;13:147-52

13. Amir Alireza RG, Afsaneh R, Seied Hosein MS, Siamak Y, Afshin K, Zeinab K, Mahvash MJ, Amir RR. Inhibitory activity of Salvadora persica extracts against oral bacterial strains associated with periodontitis: an in-vitro study. J Oral Biol Craniofac Res. 2014;4:19-2.

14. American Academy of Pediatric Dentistry. Caries-risk Assessment and Management for Infants, Children, and Adolescents. The Reference Manual of Pediatric Dentistry. Revised 2019. Available at: https://www.aapd.org/ globalassets/media/policies_guidelines/bp_cariesriskassessment.pdf. Accessed 11 Feb 2020

15. The World Health Organization website. Available at: http://www.who.int/ oral health; Accessed 25 Jan 2016.

16. Green JC, Vermillion JR. The simplified oral hygiene index. J Am Dent Assoc. 1964;68:7-13.

17. Aas JA, Griffen AL, Dardis SR, Lee AM, Olsen I, Dewhirst FE, Leys EJ, Paster BJ. Bacteria of dental caries in primary and permanent teeth in children and young adults. J Clin Microbiol. 2008;46:1407-17.

18. American Academy of Pediatric Dentistry (AAPD). Recommendations for Pediatric Oral Health Assessment, Preventive Services, and Anticipatory Guidance/Counseling. Available at: http://www.aapd.org/assets/1/7/ periodicity-aapdschedule.pdf; Accessed 9 Oct 2018.

19. Hamasha AA-H, Alshehri A, Alshubaiki A, Alssafi F, Alamam H, Alshunaiber R. Gender specific oral health beliefs and behaviors among adult patients attending king Abdulaziz Medical City in Riyadh. Saudi Dent J. 2018;30:226-3.

20. Corby PM, Lyons-Weiler J, Bretz WA, Hart TC, Aas JA, Boumenna T, Goss J, Corby AL, Junior HM, Weyant RJ, Paster BJ. Microbial risk indicators of early childhood caries. J Clin Microbiol. 2005;43:5753-9.

21. Ma C, Chen F, Zhang Y, Sun X, Tong P, Si Y, Zheng S. Comparison of Oral microbial profiles between children with severe early childhood caries and caries-free children using the human Oral microbe identification microarray. PLoS One. 2015;10:e0122075.

\section{Publisher's Note}

Springer Nature remains neutral with regard to jurisdictional claims in published maps and institutional affiliations. 